\title{
Modern solutions to historic problems: advanced materials and techniques in heritage applications
}

\author{
P. Lambert \& A. R. Foster \\ Mott MacDonald, Materials \& Corrosion Engineering, UK
}

\begin{abstract}
The maintenance and remediation of historic structures naturally lends itself to the use of traditional materials and methods. While 'like for like' remains the gold standard, there are situations that may mean alternative materials and methods need to be considered.

Many of these approaches are associated with the prevention or control of corrosion of metallic components used as reinforcement, fixings or decoration. Common alloys of iron and carbon, such as steel, cast iron and wrought iron, are totally synthetic, essential unstable and prone to corrosion. A number of electrochemical approaches are available to extend the life of metallic items.

Corrosion can also be controlled by chemical methods in the form of inhibitors. Red lead provided this form of protection but newer organic options have become available that can be used with or without a coating system.

In addition to concerns over the durability of structures, there can often be problems with their structural capacity. Fibre reinforced composites (FRC) in resin matrixes originally developed for reinforced concrete can also be applied to stone and brick masonry, timber and cast iron.

The polymer component in FRC can result in creep, poor fire performance and attack by UV, solvents and heat. Replacement of the organic matrix with an inorganic matrix could resolve such limitations and recent developments, such as geopolymers, essentially artificial rock, may be one such answer.

Finally, the rapid development in sensor and remote interrogation technology allows sensitive structures and their enhancements to be effectively monitored without detracting from the historic and aesthetic values.
\end{abstract}

Keywords: cathodic protection, electrochemical chloride extraction, realkalisation, corrosion inhibitors, fibre reinforced composites. 


\section{Introduction}

All structural materials have a finite life and at some point will require a degree of intervention. Often coatings or renders are applied to provide both protection and improved aesthetics and provided these are maintained and replaced in a sympathetic manner the originality of the structure is considered to remain unimpaired.

The inclusion of metallic items for structural or other purposes adds a degree of complication. While all metals are essentially synthetic, the ferrous alloys are particularly prone to decomposition or rusting. While gold is essentially immortal, iron and steel are not and without great care can soon perish and return to the earth from where they came [1].

Where structural capacity has also suffered it may be necessary to incorporate additional reinforcement, which may be difficult to achieve without significantly altering the appearance of the element under consideration.

By adopting a number of relatively new technologies, often originally developed for use with reinforced concrete buildings and infrastructure, it is possible to reinstate both durability and structural capacity in a sympathetic and discrete manner that should satisfy both the structural engineer and conservation professional [2].

\section{Cathodic protection of iron and steel framed structures}

Cathodic protection (CP), originally developed by Humphry Davy [3] and later employed widely on buried and submerged structures, was first considered for reinforced concrete in the late 1950's. It was not until the development of improved anode systems based on catalysed titanium and titanium oxide in the early 1980's and the considerable advances in digital operating systems that it became a serious commercial solution. The transfer to steel framed buildings was somewhat slower and it was not until 1997 that the first full structure, Gloucester Road Underground Station [4], was protected by such a system.

Steel framed masonry clad construction became popular around the turn of the $20^{\text {th }}$ century and was employed in many of the commercial and municipal buildings found in European city centres constructed between 1900 and 1940 .

Over the last 75 to 100 years, the protection offered by the surrounding masonry has broken down and the steel has corroded resulting in cracking and displacement of cladding as higher volume corrosion has filled up the gaps, as shown in Figure 1. In extreme cases, the steel members have lost sufficient section to impair their structural capacity, requiring the inclusion of new or additional steel.

In the presence of moisture and oxygen, steel and other simple ferrous alloys undergo corrosion resulting in a loss of metal and the formation of expansive corrosion products commonly known as rust. Aqueous corrosion requires two reactions to be sustained simultaneously. One reaction results in metallic iron being converted to iron ions with an associated release of electrons; this is the 'anodic' reaction. 


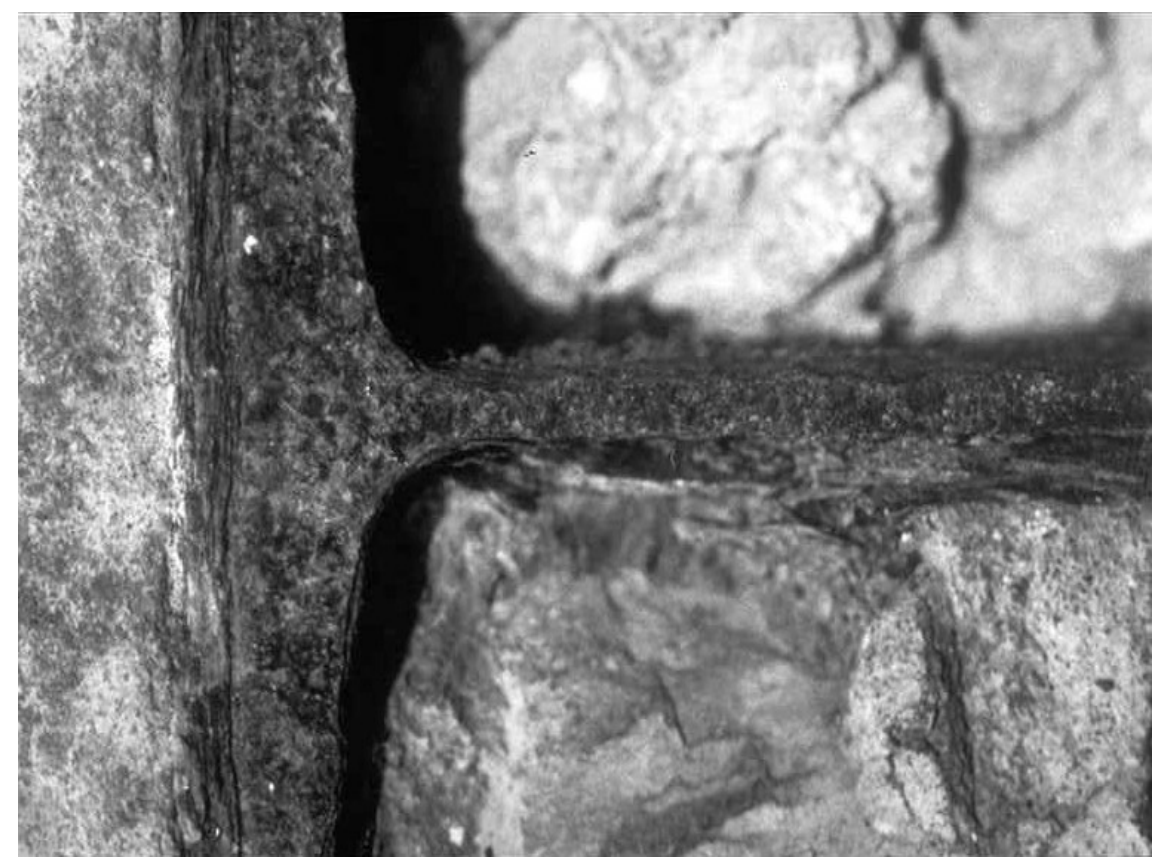

Figure 1: Corrosion of a masonry encased wrought iron beam.

At the same time in an adjacent area, these electrons are combined with water to produce hydroxyl ions which protect the steel; this is the 'cathodic' reaction. Dissolved metal ions react with hydroxyl ions to form the familiar corrosion products and the anodic areas gradually lose section [5].

Traditional methods of repair require the displaced masonry to be removed and the corroded frame to be cleaned and recoated prior to reinstating the cladding. This is not only disruptive and expensive, but generally leaves large areas of corrosion where no displacement of the masonry has occurred untreated and the level of damage to the masonry will commonly require new material to be employed in the reconstruction, thereby undermining the authenticity of the structure.

$\mathrm{CP}$ of such structures, introduced toward the end of the last century, has provided a technically feasible and commercially viable alternative to the repair and maintenance of such structures and continues to gain favour in such applications. In simple terms, cathodic protection works by making all the steel to be protected cathodic with respect to a system of installed anodes. These can be self-powered galvanic or, more commonly inert anodes powered by a low voltage DC supply. Details of such systems have been described in detail elsewhere [6].

\section{Electrochemical chloride extraction and realkalisation}

The use of $\mathrm{CP}$ can result in a number of potentially beneficial side effects. The ferrous component, being the cathode in a corrosion cell, generates hydroxyl ions 
which help maintain a passive oxide film on the surface of the steel and protect it from further corrosion. In addition, because the cathode is negatively charged, ions such as chloride are repelled from the steel and attracted to the inert anodes.

While these processes occur naturally as a consequence of $\mathrm{CP}$, they can also be optimised as remediation treatments in their own right. The claimed benefit of such techniques is that they can be applied temporarily in order to increase the alkalinity or reduce chloride levels and then be removed. This means that the affected material can be treated in situ and potentially returned to its original condition and appearance. Commercially these techniques are referred to as electrochemical chloride extraction (ECE) and realkalisation, although the former is sometimes confusingly referred to as 'desalination' [7].

Both techniques employ a temporary anode system held on the surface of the concrete within an electrolyte, either by means of tanks or in the form of a papier mâché poultice. For chloride extraction the electrolyte is commonly calcium hydroxide solution as this prevents the generation of chlorine at the anode surface. For realkalisation, the electrolyte is usually a solution of sodium or potassium carbonate which permeates into the concrete through a mixture of diffusion and electro-osmosis and helps reinstate the alkalinity of the cover concrete. Figure 2 shows San Antonio Church in Valmadrera, Italy which used realkalisation to treat badly carbonated concrete elements in the bell tower [8].

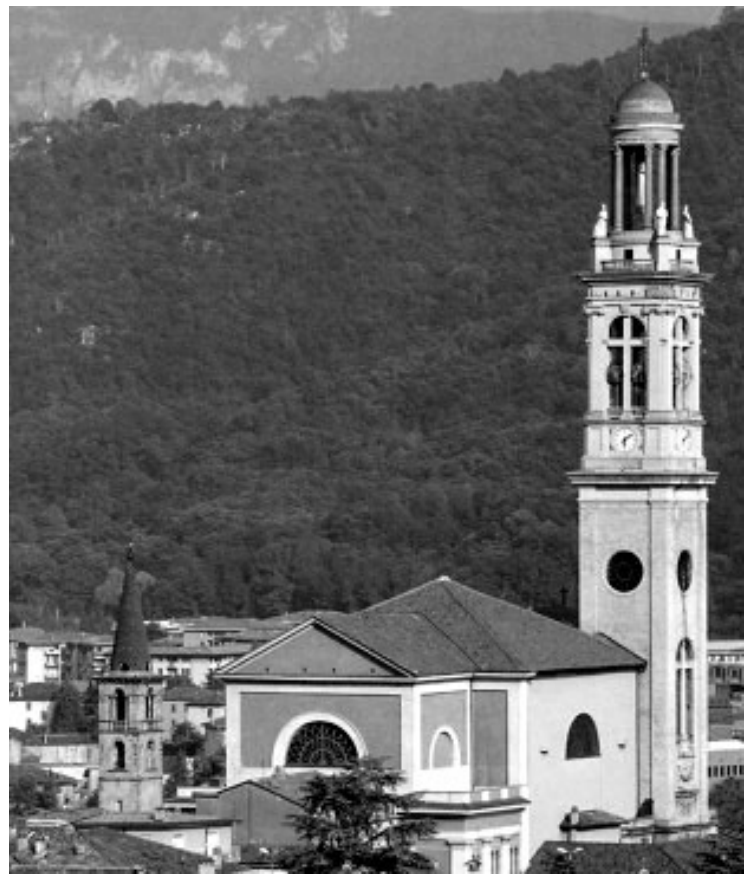

Figure 2: Realkalisation was used in the restoration of the bell tower of the Church of San Antonio in Italy [8]. 


\section{Electro-osmosis}

The application of a DC current across a porous solid can generate movement of moisture due to electro-osmosis. While techniques such as CP, ECE and realkalisation result in a small effect, electro-osmosis as a technique in its own right has been applied to the movement of moisture through porous materials such as masonry for a considerable time and with varying results. Most recent systems employ low voltage DC pulses designed to operate at maximum efficiency while avoiding problems of stray-current corrosion to adjacent metallic items.

Where reinforcement or other metallic items are present, the design, installation and monitoring of the system should prove simpler than for existing electrochemical remediation techniques. Such systems are capable of reducing moisture levels to between $60 \%$ and $70 \% \mathrm{RH}$, and maintaining this level irrespective of external weather conditions. An additional benefit to the removal of excess free moisture is the associated reduction in dissolved salts such as chlorides and sulphates.

The combination of reduced chloride ion concentration and controlled relative humidity can result in a significant reduction in corrosion rate for reinforcement or other embedded metallic items to low or negligible values. The continuing operation of an appropriately designed and installed system can prevent or control further ingress of moisture and associated dissolved salts. Additionally, if the system is designed to negatively polarise reinforcement this results in a degree of cathodic protection, helping to reduce the corrosion risk of embedded steel during the transition period from high to low relative humidity and providing additional protection throughout the life of the installation [9].

\section{Corrosion inhibitors}

Corrosion inhibitors are widely used in the protection of metals in domestic, commercial and industrial applications. A corrosion inhibitor is essentially any material that when present in a relative small quantity results in a significant reduction in the corrosion rate of metals, predominantly the ferrous based materials such as iron and steel. There has long been interest in their potential use for the protection of metallic reinforcement in concrete and other structural materials.

Inorganic inhibitors such as nitrites and benzoates have been used as anticorrosive admixtures in concrete since the 1950's, principally as admixtures introduced at the time of manufacture. A more recent development has been the development of organic inhibitor systems that can be applied to the surface which then migrate to and protect buried metallic components. These materials are commonly based on amino-alcohols and are capable of migrating through masonry and concrete to form a highly adherent microscopic film covering the surface of the metal and thereby protect it. 


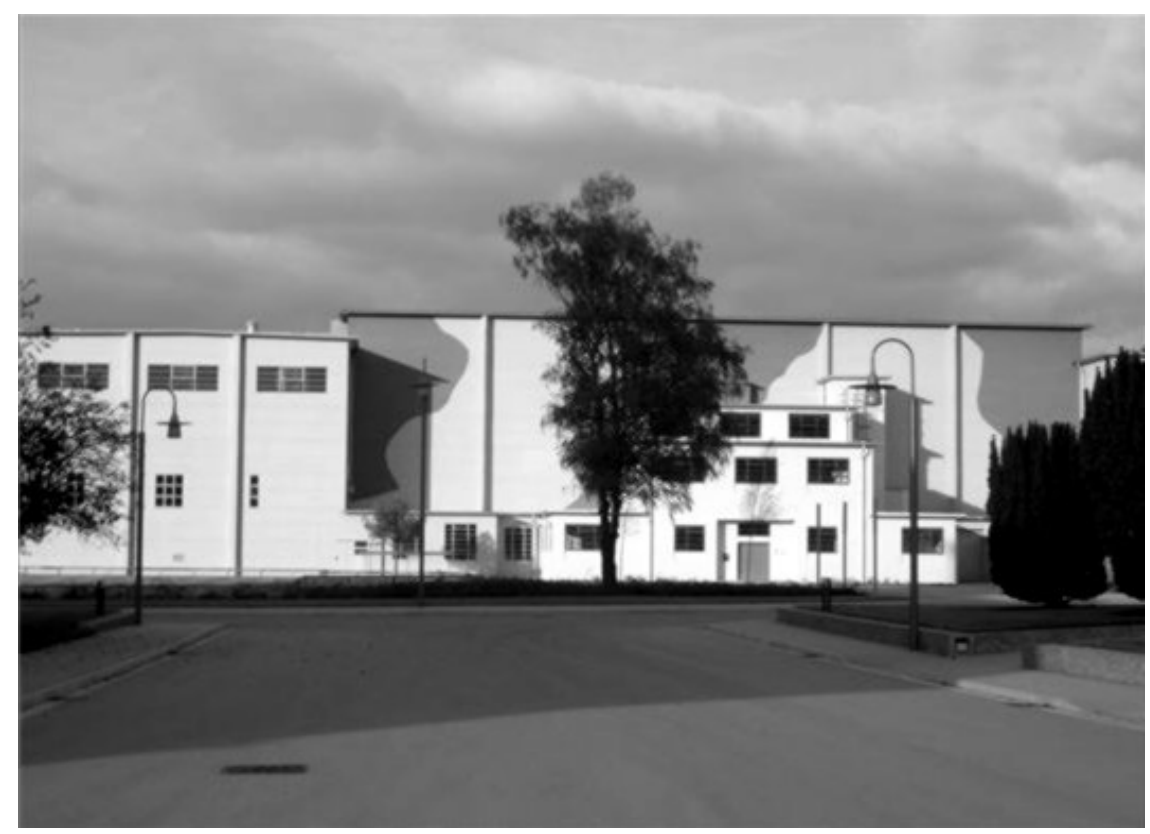

Figure 3: Wind tunnel buildings at RAE Farnborough, partly protected by inhibitors [10].

Because the surface of the porous material to which they are applied is unaltered, they allow the protection of embedded metals without altering the appearance of the structure. The service life of the inhibitor, typically several years, is dependent upon the porosity of the material and severity of the environment but can be easily reapplied. Figure 3 shows a Grade 1 listed structure at the former Royal Aircraft Establishment in Farnborough, UK where corrosion inhibitors were employed to protect the reinforcement while retaining the original weathered appearance of the concrete [10]. Other recent applications for corrosion inhibitors have included cramps and wall ties and the protection of historically important industrial sites with wax-based corrosion inhibiting coatings.

\section{Fibre reinforced composites}

Fibre reinforced composites employing glass, carbon and aramid fibres in polymer matrices are now commonly employed in the strengthening of building and civil structures and have more recently been investigated for use in historic building though research programmes such as the European EUREKA COMREHAB project [11]. In addition to the well established strengthening of steel and reinforced concrete, applications have been reported involving cast iron (see Figure 4), wrought iron, stone and brick masonry and timber [12]. 


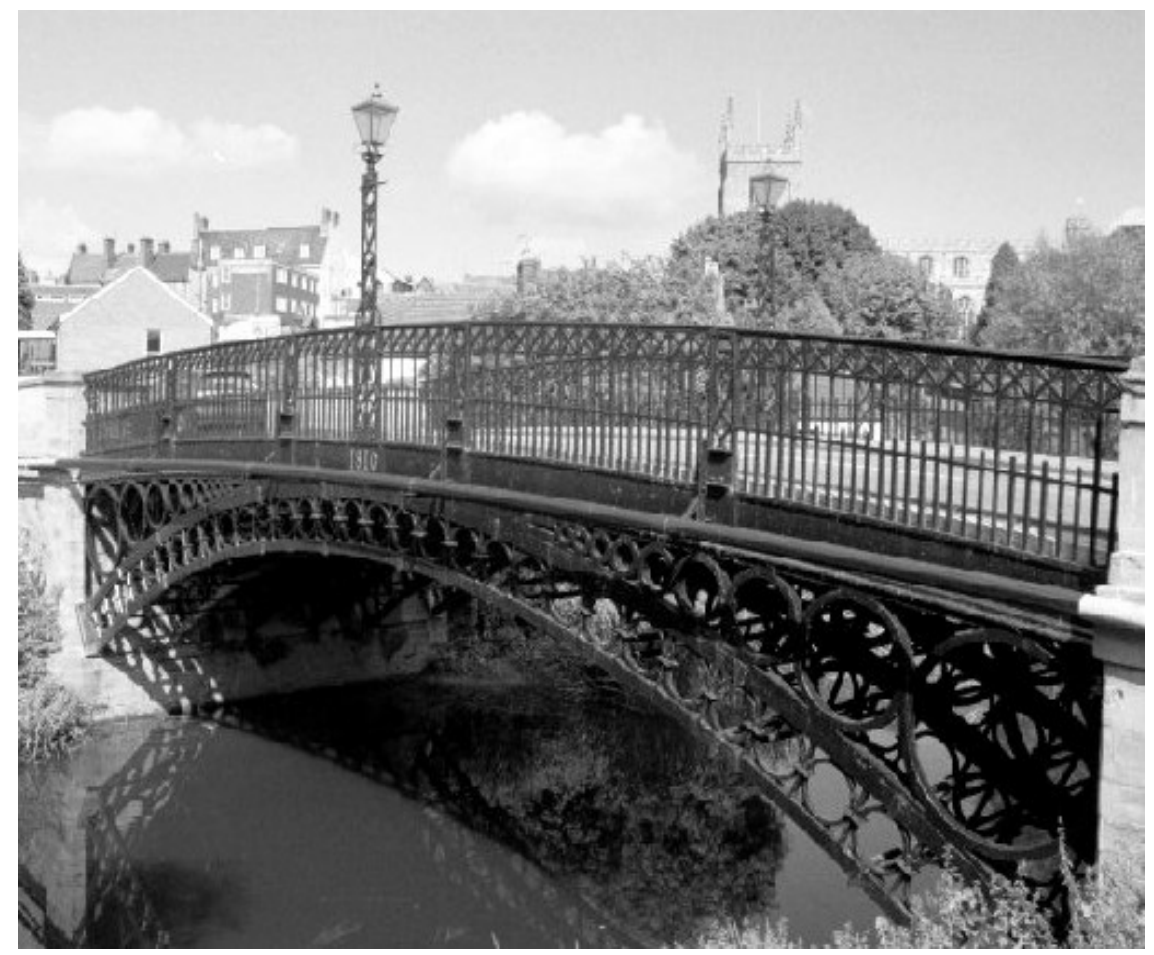

Figure 4: Tickford Bridge, Newport Pagnell, UK, strengthened with carbon fibre composites.

The main limitations with the technique relate to the limited fire resistance of the resins employed both as the matrix and as the adhesive to fix the composite to the substrate. Improvements in resin technology, fire protection and alternative binders such as geopolymers (see section 7) promise to greatly increase the scope of their use in both conventional and historic applications.

\section{Geopolymers}

Geopolymers, or inorganic polymers, are essentially artificial stone produced by reacting natural or man-made pozzolanic materials such as ash, slag and kaolin with alkaline silicate solutions. While sometimes attributed to ancient civilisations, the development of the technology is essentially modern and results in a strong, stable ceramic material that can resist high temperatures and aggressive chemical environments.

A recently reported novel application employed a geopolymer grid to reinforce a $17^{\text {th }}$ century terracotta sculpture [13]. In the longer term, geopolymers offer the possibility of fire resistant, inorganic adhesives for anchor and composite strengthening systems and as they are not prone to the sensitivity of UV and moisture displayed by organic materials may be expected to deliver very long service lives. 


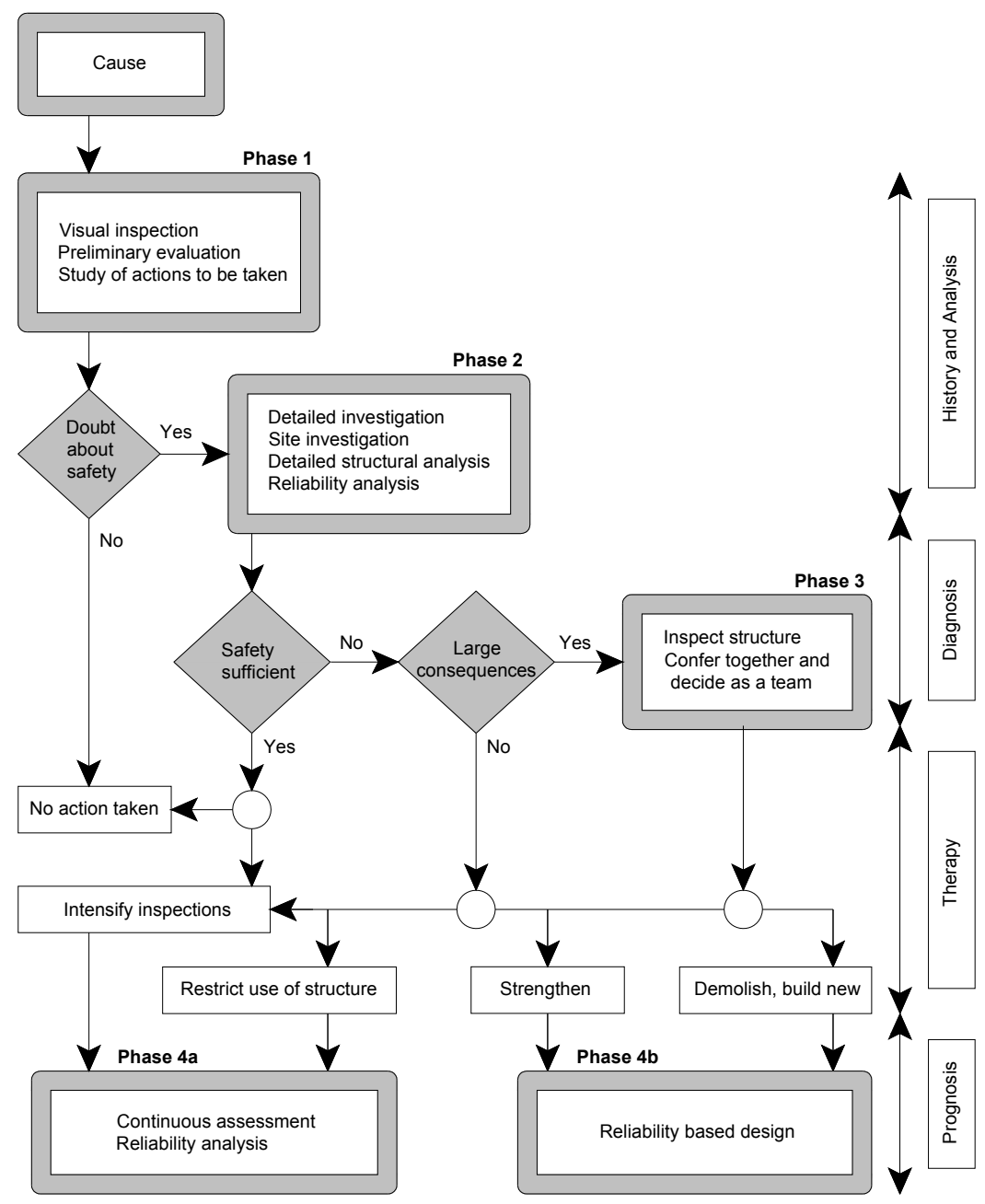

Figure 5: Global framework for the assessment of existing buildings [14].

\section{Inspection and monitoring}

There are many techniques available for the inspection and monitoring of historical structures covering a wide range of technologies and cost. The most appropriate technique for a specific structure may be a tried and tested method which has been used many times in similar situations. More often, however, a number of different approaches may be required in order to address specific concerns. Due to the sensitive nature of historical structures, any inspection or monitoring techniques employed must be non-intrusive. 
Providing there is sufficient access to the areas to be inspected, the simplest form of inspection is visual. A thorough and competent visual inspection can result in the identification of areas potentially requiring further attention, or may lead to the direct diagnosis of a problem and a suitable method of remediation. Where visual inspection is not practical a combination of several alternative techniques may be required. These could range from relatively simple methods, such as the implementation of strain gauges to monitor movement, to advanced and often expensive techniques such as radiography and magnetic techniques [14]. The results of such inspections would form part of a more global assessment procedure, as outlined in Figure 5.

\section{Conclusions}

Recently developed approaches for the inspection, testing and remediation of conventional buildings and infrastructure hold equal promise for the specialist heritage market.

Through careful selection and application it is possible to enhance the condition and durability of historic structural components without compromising the requirements for conservation, and because of the less intrusive nature of many of these techniques the original fabric of the building can be more effectively preserved.

\section{Acknowledgements}

The authors wish to thank the support and contributions made to this work by Mott MacDonald Ltd. and the Centre for Infrastructure Management, Sheffield Hallam University.

\section{References}

[1] Lambert P, 'Sustainability of metals and alloys in construction', Sustainability of Construction Materials, Woodhead Publishing, pp 148170, 2009.

[2] Jones G, Lambert P, Bolton P \& Robinson M, 'Hi tech heritage', Concrete Engineering International. pp 17-20, 1999.

[3] Davy H, 'On the corrosion of copper sheeting by seawater, and on methods of preventing this effect, and on their application to ships of war and other ships'. Proceedings of the Royal Society, 114, pp.151-246, 1824 and 115, pp.328-346, 1825.

[4] Evans B, 'Electric refurbishment', The Architects' Journal, pp 59-61, November 1997.

[5] Lambert P, 'Corrosion mechanisms - an introduction to aqueous corrosion', Corrosion Prevention Association, Technical Note No.5, 2001.

[6] Lambert P \& Atkins C P, 'Cathodic protection of historic steel framed buildings', Structural Studies, Repairs and Maintenance of Heritage Architecture XI, Malta, pp 491-500, 2005. 
184 Structural Studies, Repairs and Maintenance of Heritage Architecture XI

[7] McFarland B, 'Electrochemical repair using realkalisation and chloride extraction techniques', Concrete Repair Association Guidance Note, 1999.

[8] Bertolini L, Carsana M \& Redaelli E, 'Conservation of historical reinforced concrete structures damaged by carbonation induced corrosion by means of electrochemical realkalisation', Journal of Cultural Heritage, Volume 9, pp 376-385, 2008.

[9] Lambert P, 'Controlling moisture', Construction Repair, pp 29-32, March/April 1997.

[10] Williams N, 'Tunnel vision - historic concrete conservation', Concrete, pp $30-31$, February 2008.

[11] Borchardt J K, 'Reinforced plastics help preserve historic buildings', Reinforced Plastics, Volume 47, Issue 11, pp 30-32, December 2003.

[12] Jacob A, 'Composites offer help in the conservation of historic buildings', Reinforced Plastics, Volume 51, Issue 2, pp 30-34, February 2007.

[13] Hanzlíček T, Steinerová M, Straka P, Perná I, Siegl P \& Švarcová T, 'Reinforcement of the terracotta sculpture by geopolymer composite', Materials \& Design, In Press, 2009.

[14] Schueremans L, Van Rickstal F, Ignoul S, Brosens K, Van Balen K \& Van Geemert D, 'Continuous assessment of historic structures - a state of the art of applied research and practice in Belgium', Proceedings of the Institute of Theoretical \& Applied Mechanics, Workshop 11, Prague, 2002. 